\title{
Precision medicine based on tumorigenic signaling pathways for triple-negative breast cancer (Review)
}

\author{
NAN WU ${ }^{1,2}$, JINGHUA ZHANG $^{3}$, JING ZHAO $^{1,2}$, KUN MU $^{1,2}$, JUN ZHANG $^{1,2}$, \\ ZHAO JIN ${ }^{1,2}$, JINPU YU ${ }^{1,4}$ and JUNTIAN LIU ${ }^{1,2}$
}

\begin{abstract}
${ }^{1}$ Department of Breast Surgery, North China Petroleum Hospital, Renqiu, Hebei 062552; ${ }^{2}$ Key Laboratory of Breast Cancer Prevention and Therapy, Key Laboratory of Cancer Prevention and Therapy, Tianjin's Clinical Research Center for Cancer, National Clinical Research Center of Cancer, Tianjin Medical University Cancer Institute and Hospital, Tianjin 300060;

${ }^{3}$ Department of Surgery, North China Petroleum Hospital, Renqiu, Hebei 062552; ${ }^{4}$ Biotherapy Center, Key Laboratory of Cancer Immunology and Biotherapy, Tianjin Medical University Cancer Institute and Hospital, Tianjin 300060, P.R. China
\end{abstract}

Received February 2, 2017; Accepted January 22, 2018

DOI: $10.3892 / 01.2018 .9290$

Abstract. As a clinically heterogeneous subtype of breast cancer, triple-negative breast cancer (TNBC) is associated with a poor clinical outcome and a high relapse rate.

Correspondence to: Dr Jinpu Yu, Biotherapy Center, Key Laboratory of Cancer Immunology and Biotherapy, Tianjin Medical University Cancer Institute and Hospital, Huanhuxi Road, Hexi, Tianjin 300060, P.R. China

E-mail: yujinpu@tjmuch.com

Dr Juntian Liu, Key Laboratory of Breast Cancer Prevention and Therapy, Key Laboratory of Cancer Prevention and Therapy, Tianjin's Clinical Research Center for Cancer, National Clinical Research Center of Cancer, Tianjin Medical University Cancer Institute and Hospital, Huanhuxi Road, Hexi, Tianjin 300060, P.R. China

E-mail: ljt641024@163.com

Abbreviations: ALDH1, aldehyde dehydrogenase 1; AR, androgen receptor; BRCA, breast cancer-associated; Co-Smads, common mediator Smads; DSB, DNA double-strand break; EGFR, epidermal growth factor receptor; EMT, epithelial-to-mesenchymal transition; ER, estrogen receptor; Erk, extracellular signal-regulated kinase; FGFR, fibroblast growth factor receptor; HER2, human epidermal growth factor receptor 2; I-Smads, inhibitory Smads; IGFR, insulin-like growth factor receptor; LRP5/6, low-density lipoprotein receptor-related 5/6; MAPK, mitogen-activated protein kinase; MEK, mitogen-activated protein kinase kinase 1; mTOR, mechanistic target of rapamycin; PARP, poly(ADP-ribose) polymerase; PD-1, programmed death-1; PD-L1, programmed death-ligand 1; PDGFR, platelet-derived growth factor receptor; $\mathrm{PI} 3 \mathrm{~K}$, phosphoinositide 3-kinase; $\mathrm{PIP}_{2}$, phosphatidylinositol-4,5-diphosphate; $\mathrm{PIP}_{3}$, phosphatidylinositol3,4,5-triphosphate; PR, progesterone receptor; PTEN, phosphatase and tensin homolog; R-Smads, receptor-regulated Smads; RTKs, Receptor tyrosine kinases; SHP2, Src homology phosphotyrosyl phosphatase 2 ; TGFR- $\beta$, transforming growth factor receptor- $\beta$; TNBC, triple-negative breast cancer

Key words: triple-negative breast cancer, precision medicine, carcinogenic pathway, targeted therapy, clinical treatment
Conventional chemotherapy and radiotherapy are effective treatments for patients with TNBC. However, the prognosis of TNBC remains unsatisfactory. Therefore, a large volume of research has explored the molecular markers and oncogenic signaling pathways associated with TNBC, including the cell cycle, DNA damage response and androgen receptor (AR) signaling pathways, to identify more efficient targeted therapies. However, whether these predicted pathways are effective targets has yet to be confirmed. In the present review, potentially carcinogenic signaling pathways in TNBCs from previous reports were considered, and ultimately five tumorigenic signaling pathways were selected, specifically receptor tyrosine kinases and downstream signaling pathways, the epithelial-to-mesenchymal transition and associated pathways, the immunoregulatory tumor microenvironment, DNA damage repair pathways, and AR and coordinating pathways. The conclusions of the preclinical and clinical trials of each pathway were then consolidated. Although a number of signaling pathways in TNBC have been considered in preclinical and clinical trials, the aforementioned pathways account for the majority of the malignant behaviors of TNBC. Identifying the alterations to different carcinogenic signaling pathways and their association with the heterogeneity of TNBC may facilitate the development of optimal precision medical approaches for patients with TNBC, potentially improving the efficiency of anticancer therapy.

\section{Contents}

1. Introduction

2. Receptor tyrosine kinases and downstream signaling pathways

3. Epithelial-to-mesenchymal transition and associated pathways

4. Androgen receptor and coordinating pathways

5. DNA damage repair pathways

6. Immunoregulatory tumor microenvironment

7. Conclusion 


\section{Introduction}

Breast cancer is the leading cause of cancer-associated mortality for women. In 2012, 1.7 million people were diagnosed with breast cancer worldwide, and 521,900 succumbed to the complications (1). Given the varied prognosis and response to treatment of patients with breast cancer, the molecular classification of breast cancer has been examined to improve the understanding of this disease. Triple-negative breast cancer (TNBC), which was first reported in the literature in 2005, is a molecular subset of breast cancer. TNBC is characterized by the absence of estrogen receptor (ER), progesterone receptor (PR) and human epidermal growth factor receptor 2 (HER2) expression (2), and accounts for $16 \%$ of all breast cancer cases (3). Although TNBC tumors display relatively simple molecular phenotypes, they are inherently heterogeneous. In particular, TNBCs exhibit varying morphology, gene expression and signaling pathway activity (4); thus, they have complicated clinicopathological features, to the detriment of the prognosis of patients with TNBC. TNBC was compared with other breast cancer subtypes in a retrospective analysis; increased risks of distant relapse [hazard ratio (HR), 2.6; $\mathrm{P}<0.0001$ ] and mortality $(\mathrm{HR}, 3.2 ; \mathrm{P}<0.001)$ in the first five years were identified (5). As established endocrine and targeted therapies are ineffective against TNBC, chemotherapy remains the primary regimen for TNBC treatment (6). TNBC is highly sensitive to cytotoxic chemotherapy (7), but this treatment is associated with relatively low rates of pathological response $(8,9)$. Thus, developing a more effective therapeutic method for patients with TNBC is necessary.

With this objective, a number of studies have investigated the molecular classification of TNBC to determine optimal individualized therapy strategies for TNBC. Lehmann et al (4) indicated that TNBCs could be classified into the following subtypes according to gene expression profiles: Basal-like subtypes 1 and 2, immunomodulatory subtype, mesenchymal subtype, mesenchymal stem-like subtype, and luminal androgen receptor (AR) subtype. Alternatively, Burstein et al (10) reported that TNBCs could be divided into four subtypes: Basal-like/immune-suppressed subtype, basal-like/immune-activated subtype, mesenchymal subtype and luminal/AR subtype. Patients with specific tumor molecular abnormalities treated with molecularly matched targeted therapy respond better to therapy compared with those treated with non-matched targeted therapy (11). In the present review, the molecular markers and signaling pathways frequently dysregulated in TNBCs, and the targeted therapies in clinical trials and preclinical studies, will be summarized.

\section{Receptor tyrosine kinases and downstream signaling pathways}

RTKs are important components of signal transduction pathways in the regulation of proliferation, and are associated with two downstream signaling pathways in particular: The Ras/mitogen-activated protein kinase (MAPK) pathway, and the phosphoinositide 3-kinase (PI3K)/AKT/mechanistic target of rapamycin (mTOR) pathway. The RTKs include epidermal growth factor receptor (EGFR), vascular endothelial growth factor receptor (VEGFR) 1-3, platelet-derived growth factor receptor (PDGFR) $\alpha / \beta$, insulin-like growth factor receptor (IGFR), fibroblast growth factor receptor (FGFR), c-Met, and transforming growth factor receptor- $\beta$ (TGFR- $\beta$ ), all of which are potential targets for TNBC therapy $(4,12-16)$. EGFR dysregulation is the most commonly identified in TNBC tumors; $60-80 \%$ of TNBC tumors demonstrate EFGR overexpression $(17,18)$. However, the applicability of anti-RTK drugs against TNBC are limited on account of biochemical multiplicity and toxicity (19). For example, lapatinib, a dual EGFR and HER2 TK inhibitor, is ineffective in patients with TNBC, although it is clinically effective against HER2-positive breast cancer. The mechanism of lapatinib resistance in TNBC may be associated with interleukin-6 expression (20). The inhibition of Src homology phosphotyrosyl phosphatase 2 (SHP2), an important molecule in EGFR/FGFR1/c-Met signaling (21), was reported to suppress TNBC tumorigenesis and metastasis in vitro (22), indicating the potential anti-tumor efficiency of RTK inhibitors in TNBC treatment. A number of RTK inhibitors have also exhibited promising anticancer therapeutic efficacy in a clinical setting. For example, bevacizumab is an anti-VEGF monoclonal antibody. In a single-arm and phase II multicenter study of bevacizumab, docetaxel, and carboplatin-based neoadjuvant treatment for patients with stage II/III TNBC, the results demonstrated a relatively high pathological complete response rate $(42 \%)$ with a low risk of adverse events (23); additionally, adding bevacizumab to neoadjuvant chemotherapy regimens improved the pathological complete response rate among patients with TNBC (39.3 vs. 27.9\%; $\mathrm{P}=0.003)(24)$.

Ras/MAPK pathway. The Ras/MAPK pathway promotes cell proliferation, cell differentiation and angiogenesis (25). Ras family members, including H-Ras, K-Ras and N-Ras, can be activated by RTKs to transmit growth signals from the cell membrane to the nucleus via a series of phosphorylated proteins, including Raf, MAPK kinase 1 (MEK) and extracellular signal-regulated kinases (ERK) 1/2 (26). Although the frequency of mutations in the Ras/MAPK signaling pathway is $<2 \%$ in TNBC, copy number variations of certain genes from the Ras/MAPK pathway have been demonstrated to be associated with TNBC (26). For example, the overexpression of ERK is associated with a higher mortality rate in patients with TNBC (27). The MEK inhibitor selumetinib inhibited the motility and invasiveness of the MDA-MB-231 and SUM149 TNBC cell lines in vitro. In addition, selumetinib had a significant effect on the prevention of lung metastasis in a TNBC-bearing mouse xenograft model (25). These findings may provide evidence of the applicability of MEK inhibitors in TNBC treatment. However, certain genetic defects along the Ras/MAPK pathway, including the loss of negative regulators of MAPK signaling, such as phosphatase and tensin homolog (PTEN) and certain regulatory micro (mi)RNAs, such as the let-7 family, are also proposed to serve an important role in TNBC development (26). The Ras/MAPK pathway negatively regulates tumor immunogenicity by affecting the process of tumor antigen presentation in TNBC cells; compared with solo therapy, combining MEK inhibition and programmed death-1 (PD-1)/programmed death ligand 1 (PD-L1) immune checkpoint inhibitors increased the therapeutic efficiency in a murine syngeneic TNBC model (28). 
PI3K/AKT/mTOR pathway. PI3K family members are activated by RTKs. Activated PI3Ks phosphorylate phosphatidylinositol-4,5-diphosphate $\left(\mathrm{PIP}_{2}\right)$ to phosphatidylinositol-3,4,5-triphosphate $\left(\mathrm{PIP}_{3}\right)$, resulting in the downstream phosphorylation of AKT (29). Phosphorylated AKT then activates mTOR, a serine/threonine protein kinase, through the intermediary tuberous sclerosis complex $1 / 2$ to promote protein synthesis and cell growth $(30,31)$. PTEN serves an important tumor suppressor role in the process by inhibiting the dephosphorylation of $\mathrm{PIP}_{3}$ to $\mathrm{PIP}_{2}$ (32). The $\mathrm{PI} 3 \mathrm{~K} / \mathrm{AKT} / \mathrm{mTOR}$ pathway mediates a range of processes, including cell growth, survival and migration, and tumor formation and angiogenesis (33). The dysregulation of the $\mathrm{PI} 3 \mathrm{~K} / \mathrm{AKT} / \mathrm{mTOR}$ pathway occurs frequently in TNBC. PI3KC $\alpha$-activating mutations are observed in $23.7 \%$ of TNBC patients (34), and PTEN loss mutations, including promoter silencing and functional suppression, are detected in $25-30 \%$ of TNBC cases $(32,35,36)$. With regards to outcome, the hyperactivation of $\mathrm{AKT}$ and $\mathrm{mTOR}$ are associated with the poor prognosis of patients with TNBC, and based on success in preclinical experiments, dual inhibition of these molecules may represent a promising strategy for TNBC treatment (37-39).

The mTOR inhibitor everolimus has been approved by the US Food and Drug Administration (FDA), and can be combined with the aromatase inhibitor exemestane for patients with metastatic homologous recombination (HR)-positive breast cancer (40). The therapeutic effect of everolimus has been confirmed for patients with TNBC; mTOR activation may lead to platinum therapy resistance (41), and so everolimus combined with carboplatin has been proposed as an effective therapy for patients with metastatic TNBC (42). Phase I trials have also demonstrated that patients with metastatic TNBC who received a combination of chemotherapy and PI3K/AKT/mTOR inhibitor-based targeted therapy had a significantly prolonged median PFS time compared with patients who did not receive the targeted therapy (43). Another study reported that $\mathrm{PI} 3 \mathrm{~K}$ inhibition causes $\mathrm{HR}$ impairment and increased sensitivity to poly(ADP-ribose) polymerase (PARP) inhibition in TNBC without breast cancer associated (BRCA) $1 / 2$ mutations. Therefore, PI3K inhibition can improve the therapeutic efficiency of PARP inhibition in BRCA-wild type TNBC (44). Based on this observation, a clinical trial with BKM120 (buparlisib) and olaparib was initiated, as presented in Table I (45-67).

A high level of crosstalk between the Ras/MAPK and $\mathrm{PI} 3 \mathrm{~K} / \mathrm{AKT} / \mathrm{mTOR}$ pathways has been detected in basal-like breast cancer models (68), and an approach that inhibits both pathways may be feasible. However, the high toxicity levels of such an approach are concerning (69), so a greater understanding of the cross-talk mechanisms between pathways is required before effective targeted therapy of this type with improved tolerability can be developed.

\section{Epithelial-to-mesenchymal transition and associated pathways}

EMT is an essential biological process that also assists the migration and invasion of malignant tumor cells. Thus, elucidating the molecular mechanism of the EMT process and its association with the occurrence, development and metastasis of cancer is of great significance.

During EMT, epithelial cells lose the expression of E-cadherin and acquire mesenchymal markers, including vimentin (70). There is evidence to indicate that a number of RTKs, including EGFR, IGF1R, hepatocyte growth factor receptor and c-Met, non-RTKs, including Src, and embryonic transcription factors, including Twist and Slug (71-77), can induce EMT. Diverse signaling pathways, including MAPKs, PI3K and nuclear factor- $\kappa \mathrm{B}$, also promote EMT $(76,78)$. Other pathways, including Notch and Wnt/ $\beta$-catenin signaling pathways, are also associated with EMT (79). Tumor cells undergoing EMT may acquire stem cell-like phenotypes and migratory abilities (80). Previous studies have indicated that the genes involved in EMT and conversion to the cancer stem cell phenotype are activated in TNBC $(4,81)$. Additional studies have demonstrated that EMT may induce the resistance to chemotherapy and radiotherapy (82), and may thus have potential as a therapeutic target in TNBC.

In preclinical trials, miRNAs have been demonstrated to regulate tumor EMT and metastasis by inhibiting the expression of certain genes (83). For example, a previous study indicated that miR-200b-3p and miR-200b-5p synergize to suppress TNBC cell migration by inhibiting EMT (84). This finding may provide a novel strategy for clinical treatment. Furthermore, protein tyrosine kinase 6 (PTK6) is an intracellular non-receptor kinase that can promote EMT and regulate the metastasis of TNBC cells by modulating E-cadherin expression. PTK6 inhibition may prevent the metastasis of TNBC cells, and thus exhibits clinical potential for improving the treatment strategies for patients with mesenchymal TNBC (85). Considering the association of EMT with breast cancer stem cells (80), aldehyde dehydrogenase 1 (ALDH1) inhibitors were proposed as a therapeutic alternative in TNBC therapy, targeting the characteristic ALDH1 phenotypic marker of breast cancer stem cells $(86,87)$. A preclinical study confirmed that LBH589, a histone deacetylase inhibitor, could inhibit the metastasis of TNBC cells by partially reversing EMT (88).

Wnt/ $\beta$-catenin pathway. Aberrant regulation of the Wnt signaling pathway serves an important role in tumorigenesis (89). This regulation is associated with EMT and self-renewal in breast cancer, as it regulates the transcription factors Twist and Slug $(90,91)$.

During tumorigenesis, the Wnt ligand binds to Frizzled $(\mathrm{Fz})$, a seven-pass transmembrane surface receptor, and its co-receptor, low-density lipoprotein receptor-related 5/6 (LRP5/6), to form a Wnt-Fz-LRP6 complex. The combination of this complex with the protein Dishevelled can elicit the phosphorylation of LRP6 and the recruitment of the axin complex, which is composed of axin, anaphase-promoting complex, casein kinase 1 and glycogen synthase kinase 3 . These events ultimately stabilize $\beta$-catenin, which is degraded by the axin complex without Wnt. The $\beta$-catenin protein is transferred to the nucleus where it activates the transcription of Wnt target genes (92).

Lehmann et al (4) demonstrated that TNBC has a unique Wnt/ $\beta$-catenin pathway gene expression. Other studies have indicated that the activation of the Wnt pathway is 


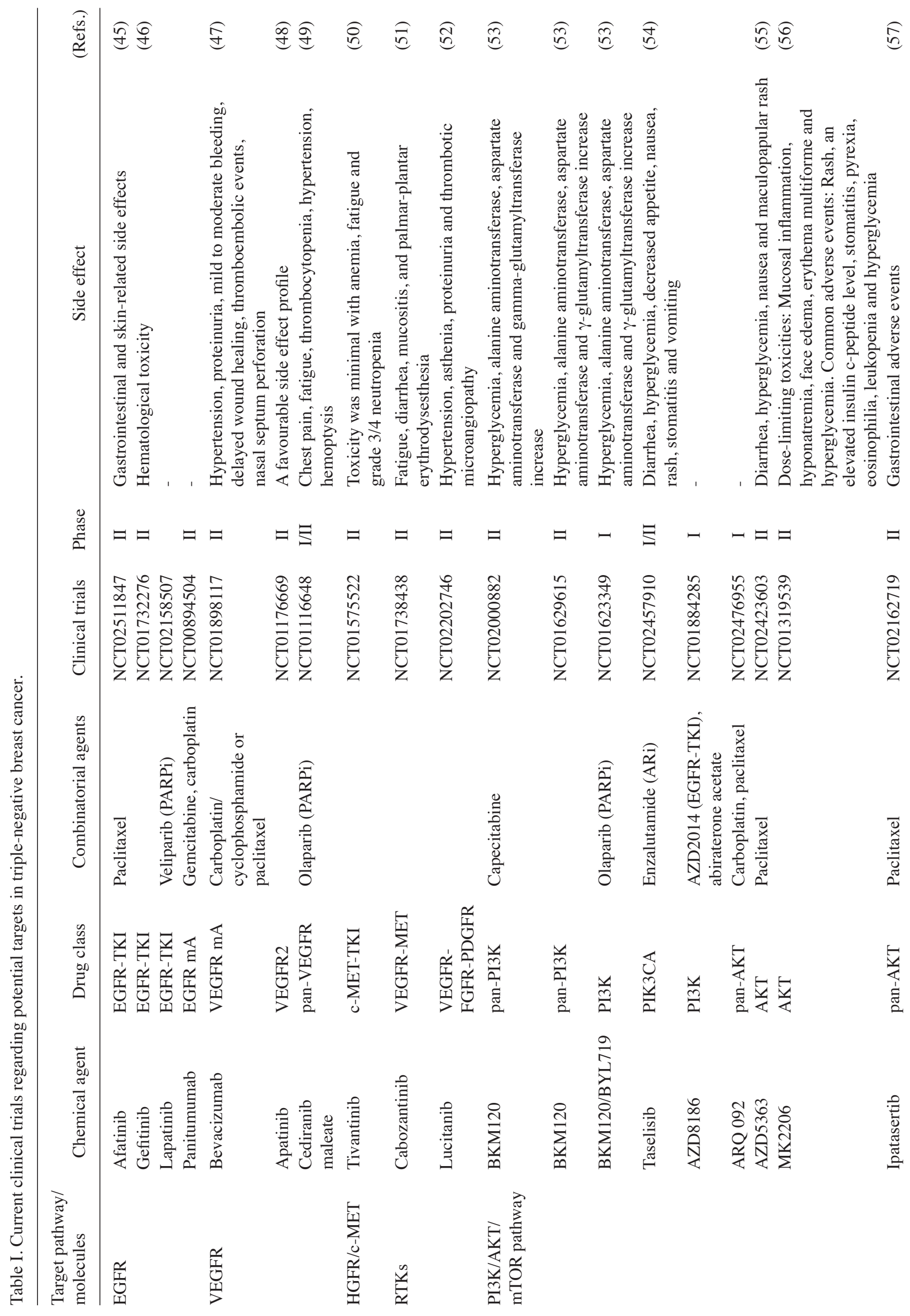




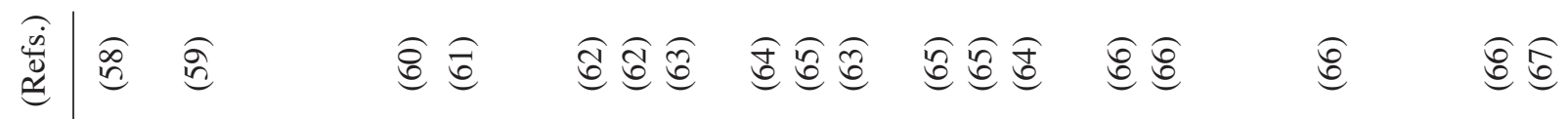

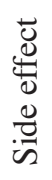

葛

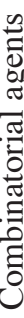

$\frac{0}{2}$

D

䢘

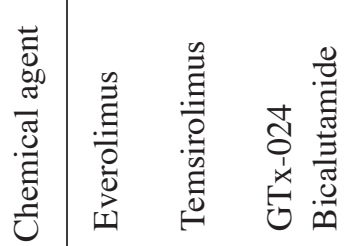

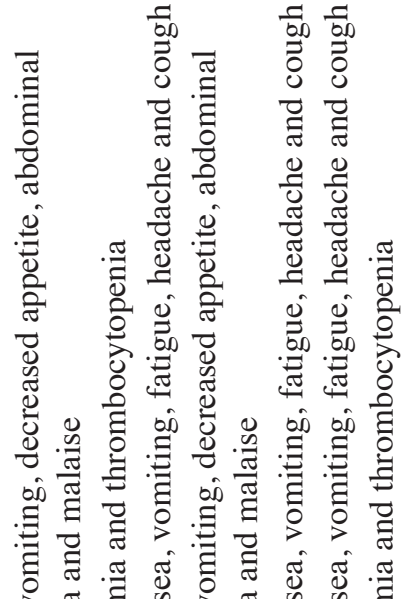

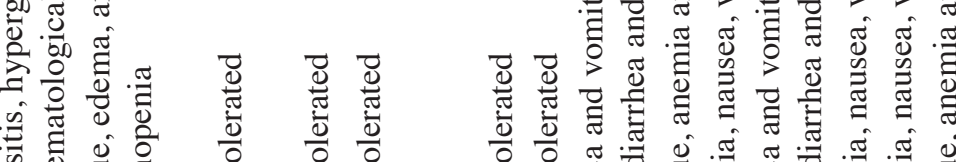

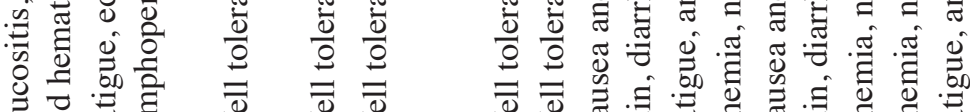

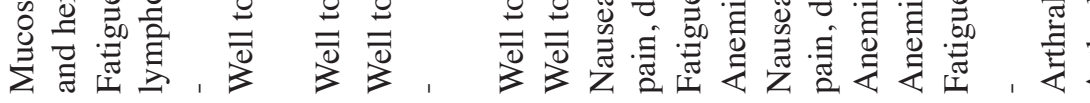

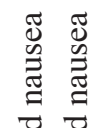

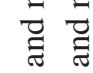

$\frac{\pi}{\frac{\pi}{60}} \cdot \frac{\pi}{\frac{\pi}{\pi}}$

当

$\stackrel{8}{0}$

.

亭

.



迅

즘

च

. $\frac{\pi}{\frac{\sigma}{\sigma 0}} \quad \frac{\pi}{\sigma 0}$

坣

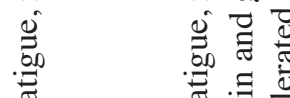

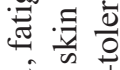

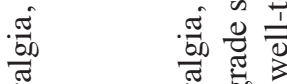

焉各范

E

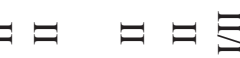

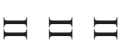

ーニ

ーーシミコー

$\Xi \quad \exists \Xi$

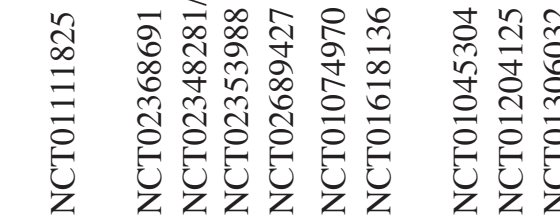

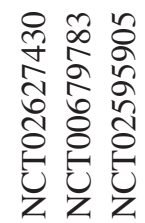

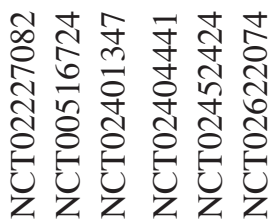

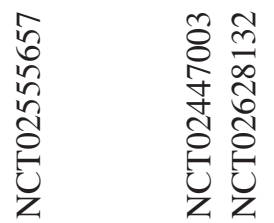

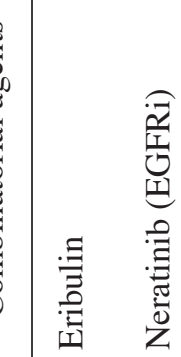

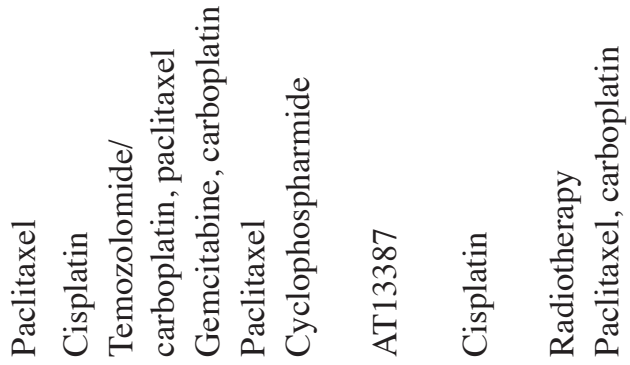

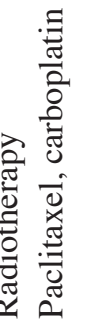

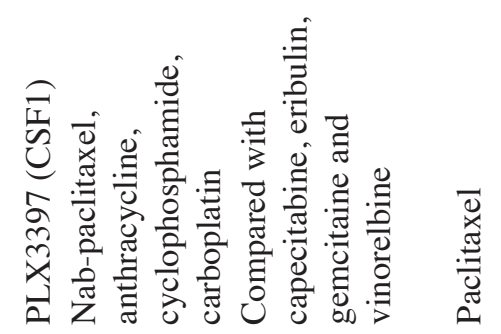

兴

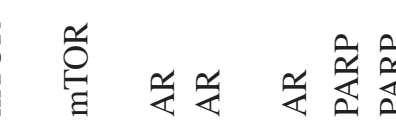

彥完

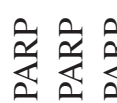

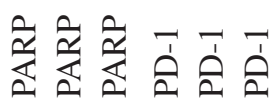

$\bar{a}$

完完

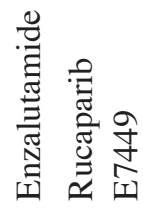

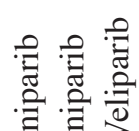

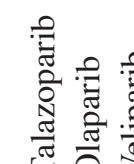

藏

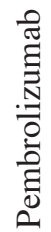

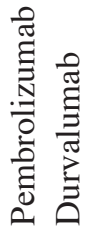


associated with poor prognosis and metastasis in patients with TNBC (93). Thus, the Wnt/ $\beta$-catenin pathway could be utilized as a target for TNBC therapy. Substantial efforts targeting the Wnt pathway have been made, but few have reached the clinical trial stage thus far. LGK974, a molecular inhibitor of Wnt secretion, has been evaluated in stage I trials in several types of cancer, including TNBC (http://www.clinicaltrials.gov). In preclinical trials, a previously FDA-approved anti-helminthic drug niclosamide, which can reduce LRP6 and $\beta$-catenin levels in vitro, was reported to suppress the growth of basal breast cancer xenografts in vivo $(94,95)$. Thus, niclosamide may be a promising drug for clinical trials. Another FDA-approved, anti-leprosy drug, clofazimine, was observed to suppress the growth of TNBC cells through the inhibition of the $\mathrm{Wnt} / \beta$-catenin pathway (94). Notably, the multipurpose drug suramin can inhibit the Wnt signaling pathway and the proliferation of TNBC cells in vitro and in vivo. Such findings may pave the way for the discovery of novel targeted therapies against Wnt-dependent TNBC tumors (96).

TGF- $\beta /$ Smad pathway. In addition to the Wnt pathway, the TGF- $\beta /$ Smad pathway can also regulate cell proliferation, invasion, apoptosis and metastasis, and induce EMT, and thus has potential in targeted strategies against TNBC (97). When secreted from cells, TGF- $\beta$ remains as an inactive, latent homodimeric polypeptide (98). TGF- $\beta$ can be activated by hydrolyzing the latent complex. The TGF- $\beta$ then binds to and activates its receptors, TGF- $\beta$ receptor type II (T $\beta$ RII) and I (T $\beta R I)$, which are transmembrane serine/threonine kinases. This induces two T $\beta R I$ and two T $\beta$ RII molecules to form a heterotetramer, and T $\beta \mathrm{R} I \mathrm{II}$ triggers the cross-phosphorylation of T $\beta R I$, allowing the activation of substrate Smad proteins (99). Smads include receptor-regulated Smads (R-Smads), common mediator Smads (Co-Smads) and inhibitory Smads (I-Smads). Among the Smad types, Smad-2 and Smad-3, as R-Smads, are the direct substrates of T $\beta R I$. The activated R-Smads combine with Smad-4, a Co-Smad, where they induce the activation of specific genes. Inversely, Smad-7, as an I-Smad, can inactivate the TGF- $\beta /$ Smad pathway by disrupting the combination of R-Smad with T $\beta R I$ (100).

Smad-2 or Smad-3 overexpression, when combined with Smad-4, can induce EMT. Inversely, the reduced expression of Smad-2, Smad-3 and Smad-4, or the overexpression of Smad-7, can constrain EMT (101). Clinical evidence suggests that $\sim 40 \%$ of human breast cancer tumors have high TGF $\beta 1$, TGF $\beta 2$, Smad-3 and Smad-4 expression levels, although the positive TGF $\beta$ gene signature occurs primarily in ER-positive breast tumors and lung metastases (102). In addition, a high TGF- $\beta 1$ expression level was detected in TNBC cells (MDA231, Hs578T, HCC1806) compared with non-TNBC (BT474, ZR75-1, SKBR3) (103). Treatment with zerumbone may inhibit the tumorigenicity of TNBC cells by suppressing the TGF $/$ /Smad pathway, and thus has a potential as a targeted drug for TNBC. LY2109761, another selective T $\beta$ RI/II dual inhibitor, can also suppress the invasion and motility of TNBC cells (103). The antidiabetic agent metformin can hinder the TGF- $\beta /$ Smad pathway by disrupting the activation of Smad-2 and Smad-3 in TNBC (104). This finding may offer a novel perspective for the clinical treatment of TNBC patients. 
Although chemotherapy is the central treatment methodology against TNBC, patients with TNBC are likely to eventually develop drug resistance and disease recurrence, which is contributed to by cancer stem-like cells. The T $\beta R I$ inhibitor LY2157299 can constrain the development of stem-like cells, indicating the potential combination of chemotherapy and TGF- $\beta$ targeted drugs in clinical trials (105).

\section{Androgen receptor and coordinating pathways}

ER and PR are widely accepted molecular markers in the occurrence, development and prognosis of breast cancer. TNBC tumors lack ER and PR expression. An association between TNBC and AR, another hormone receptor, has been observed (4). Lehmann et al (4) classified cases of TNBC according to gene expression profiling, in which a luminal AR subtype, featuring increased gene expression in the AR signaling pathway, was identified. In another study of 593 TNBC cases, a luminal AR subtype was also identified based on the expression profiles and histopathological features of primary TNBC tumors (106).

As a member of the steroid hormone receptor family, AR is expressed in $\sim 77 \%$ of breast cancer tumors (107), and serves an important role in regulating cell proliferation (108). Testosterone, particularly dihydrotestosterone, is the main activator of AR (109). Subsequent to ligand binding, AR is usually bound to chaperone proteins, including heat shock proteins, before forming a homodimer. The homodimer translocates to the nucleus and promotes the transcription of target genes (110).

Anti-androgens are the most common drugs for treating AR-positive cancer, including AR-positive TNBC. In recent research, bicalutamide (150 $\mathrm{mg}$ daily) was prescribed to 424 patients with AR-positive, ER and PR-negative metastatic breast cancer. The six-month clinical beneficial rate was $19 \%$ [95\% confidence interval (CI), 7-39\%], and the median progression-free survival time was 12 weeks $(95 \% \mathrm{CI}$, 11-22 weeks). These findings provided evidence in favor of the application of anti-androgen therapy in ER/PR-negative and AR-positive breast cancer (111). In a phase II clinical trial of enzalutamide, another AR antagonist, considerable beneficial therapeutic efficiency was demonstrated in AR-positive TNBC patients, indicating the potential efficacy of anti-AR therapy in clinical settings (clinicaltrials.gov: NCT01889238).

A previous study indicated that the concomitant administration of the anti-androgen bicalutamide with a EGFR, PDGFR $\beta$ or Erk1/2 inhibitor significantly decreased the AR expression level when compared with the single administration of the inhibitors (112). Another study reported that activating PIK3CA mutations are enriched in AR-positive TNBCs, potentially providing a basis for the concomitant use of AR antagonists with PI3K/mTOR inhibitors (4). In addition, enhanced therapeutic effects of bicalutamide combined with the PI3K inhibitor GDC-0941 (pictilisib) or the mTOR inhibitor GDC-0980 (apitolisib) have also been also observed in MDA-MB-453 and CAL-148 luminal AR subtype cell xenografts, indicating that the inhibitors targeting the PI3K/mTOR signaling pathway also notably decrease the amount of AR protein (113). It was concluded that AR expression can be regulated post-transcriptionally by activating the RTK, PI3K or Erk1/2 signaling pathways (113). The combination of anti-androgen therapy with targeted therapy against the RTK, PI3K and Erk1/2 signaling pathways may be a promising alternative treatment for AR-positive TNBC.

\section{DNA damage repair pathways}

The DNA damage response has recently attracted considerable attention in cancer research. Three major pathways operate in this process: DNA repair mechanisms that remove DNA lesions, cell cycle checkpoints that prevent the growth of cells with DNA damage and apoptotic pathways that eliminate cells with irreparable DNA lesions (114). Among the various types of DNA damage, DNA double-strand breaks (DSB) are of particular interest on account of their function in genomic instability, which promotes tumorigenesis (115). DSB repair is accomplished through the HR or non-homologous end-joining pathways (116). BRCA1 and BRCA2 are critical genes modulating DSB repair through HR (117).

TNBC is commonly associated with BRCA1/2 mutations. A germline mutation in BRCA1 or BRCA2 is present in $\sim 15 \%$ of patients with TNBC; TNBC cases account for $70 \%$ of cases of breast cancer with BRCA1 mutation, and $16-23 \%$ of those with BRCA2 mutation (118). TNBC also has similar clinical and pathological features as breast cancer with a BRCA1/2 mutation. For instance, the patients are more likely to be young and present with a high grade and lymph node invasion ratio $(119,120)$. In addition, BRCA1/2 mutations have been confirmed to be indicators of a poor TNBC prognosis (121). In a study of 182 women with TNBC, $>50 \%$ were carrying inherited BRCA1 mutations, thus demonstrating the close association between TNBC and BRCA1 (122).

Polyadenosine 5'-diphosphoribose produced by PARP enzymes serves an important role in the repair of DNA damage (123). Where there is a defect in DNA repair genes, such as BRCA in TNBC, a PARP inhibitor may be a desirable choice for therapy. In an open-label phase II clinical study, results indicated that the combination of PARP inhibitor iniparib and conventional chemotherapy drugs, including gemcitabine and carboplatin, could produce significant clinical benefit rates (from 34 to $56 \% ; \mathrm{P}=0.01$ ) and a high overall response rate (from 32 to $52 \% ; \mathrm{P}=0.02$ ) in patients with TNBC. The median progression-free and overall survival times were also prolonged, with an extension from 3.6 to 5.9 months (progression HR, 0.59; $\mathrm{P}=0.01$ ) and from 7.7 to 12.3 months (mortality HR, 0.57; P=0.01), respectively (124). In addition, in a phase I trial of the oral PARP inhibitor olaparib for metastatic TNBC, 7 (37\%) out of 19 patients receiving olaparib in combination with weekly paclitaxel had confirmed partial responses (125). Data regarding the safety of PARP inhibitor treatment for advanced TNBC and/or BRCA-mutated breast cancer from clinical trials is summarized in Table I; the side effects of PARP inhibitors are well tolerated. Interestingly, in the TNBC patients with BRCA downregulation, the sensitivity to PARP inhibitor treatment was enhanced when combined with PI3K inhibition, as the blockade of PI3K impaired HR, inducing sensitization to PARP inhibitors (44), providing a theoretical basis for the combination of PI3K with PARP inhibitors for these patients.

In addition to the aforementioned BRCA1/2 genes, other breast cancer predisposition genes, including RAD51D, 


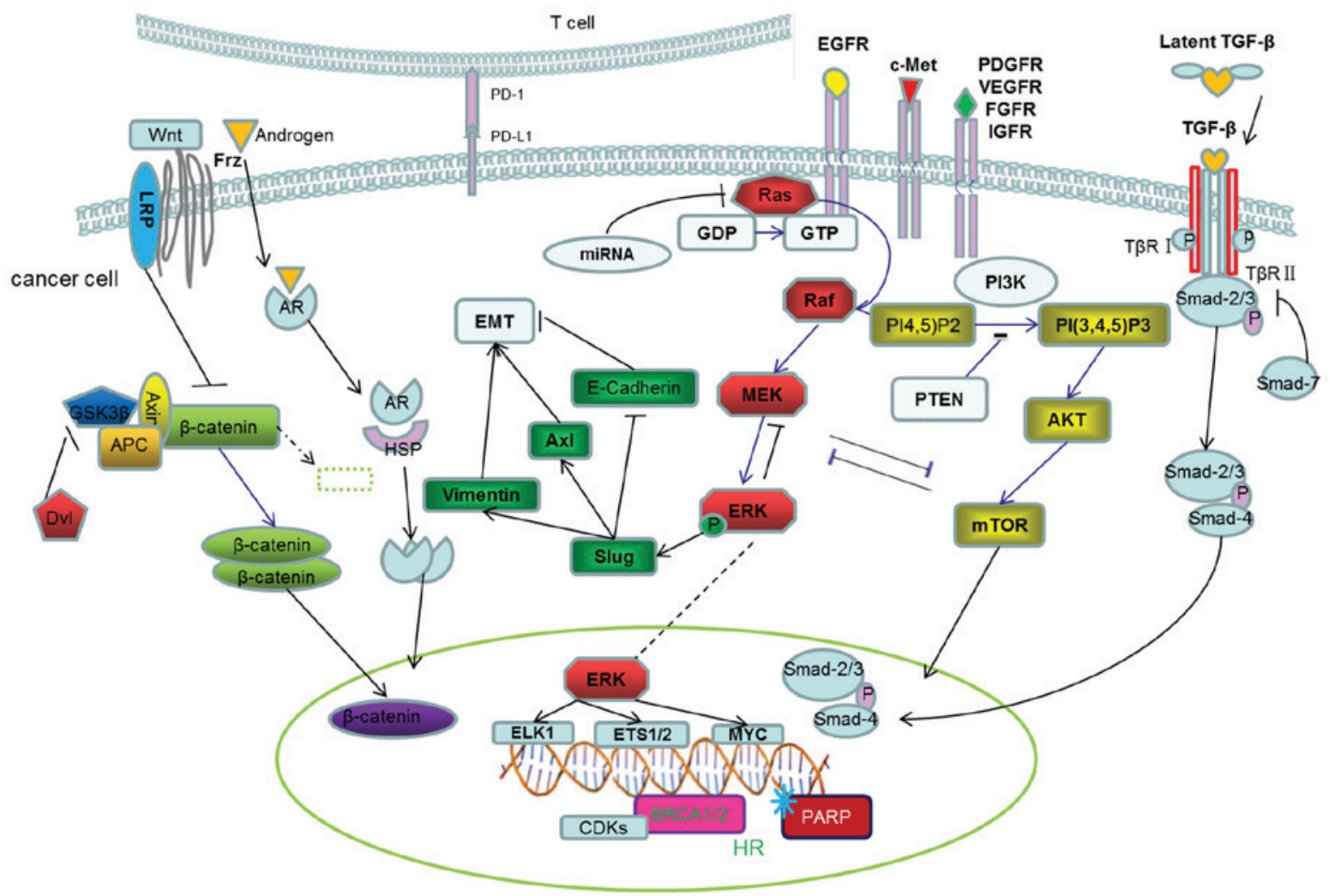

Figure 1. Molecular mechanisms of TNBC. RTKs promote tumorigenesis through the Ras/mitogen-activated protein kinase and PI3K/Akt/mTOR pathways. The phosphorylation of ERK, the Wnt/ $\beta$-catenin pathway and the TGF- $\beta /$ Smad pathway activates EMT, and regulates the migration and invasion of tumor cells. In the AR pathway, AR can bind to chaperone proteins to promote the transcription of target genes in the nucleus. At the genetic level, BRCA1/2 mutations can also promote the development of TNBCs. In the tumor microenvironment, tumor-infiltrating lymphocytes and the immune checkpoint system can allow evasion from recognition by the host immune system. TNBC, triple negative breast cancer; RTK, receptor tyrosine kinase; PI3K, phosphoinositide 3-kinase; mTOR, mechanistic target of rapamycin; ERK, extracellular signal-regulated kinase; TGF, transforming growth factor, EMT, epithelial-mesenchymal transition; AR, androgen receptor; BRCA, breast cancer-associated; PD-(L)1, programmed death (ligand) 1; EGFR, epidermal growth factor receptor; PDGFR, platelet-derived growth factor receptor; VEGFR, vascular endothelial growth factor receptor; FGFR, fibroblast growth factor receptor; IGFR, insulin-like growth factor receptor; LRP, LDL receptor-related protein; Frz, Frizzled; T $\beta R$, transforming growth factor $\beta$ receptor; miRNA, microRNA; GSK3 $\beta$, glycogen synthase kinase 3 $\beta$; HSP, heat shock protein; MEK, mitogen-activated protein kinase kinase 1; PIP 2 , phosphatidylinositol 4,5-bisphosphate; PTEN, phosphatase and tensin homolog; Dvl, Dishevelled; CDKs, cyclin-dependent kinase; HR, homologous recombination; PARP, poly(ADP-ribose) polymerase.

MRE11A, checkpoint kinase 2, mutL homolog 1, mutS homolog 6 and partner and localizer of BRCA2, have been confirmed to be associated with the development and progression of TNBC (126). It was previously reported that the cytoplasmic expression and lack of nuclear expression of RAD51 were associated with TN phenotypes, the aberrant expression of BRCA1 and a poor prognosis for patients (127), indicating that RAD51 may be a promising biomarker for selecting patients who are suitable for treatment with DNA-damaging agents.

\section{Immunoregulatory tumor microenvironment}

An increasing number of studies have demonstrated that the tumor microenvironment, particularly the immune microenvironment, is associated with the development and progression of breast cancer (128). Lehmann et al (4) and Burstein et al (10) reported that a subtype of TNBC displayed upregulated immunological responses, immune cell markers and immune transcription factors, implying the dysregulation of immune pathways in TNBC, and that the immunotherapeutic approach may be a valuable treatment strategy for patients with TNBC $(4,10)$.
Tumor infiltrating lymphocytes. High levels of stromal lymphocytic infiltration was confirmed to be associated with improved TNBC prognosis in two adjuvant phase III trials. Results of one trial indicated that compared with the patients who had a lower level of stromal lymphocytic infiltration, patients with high lymphocytic infiltration had a $14 \%$ reduced risk of recurrence $(\mathrm{P}=0.02)$, an $18 \%$ reduced risk of distant recurrence $(\mathrm{P}=0.04)$ and a $19 \%$ reduced risk of mortality $(\mathrm{P}=0.01)$ for every $10 \%$ increase in stromal lymphocytic infiltration (129). Another phase III randomized adjuvant breast cancer trial reported similar results, indicating that an increase in lymphocytic infiltration was associated with an improved prognosis in node-positive and ER-negative/HER2-negative breast cancer, regardless of chemotherapy (130). In addition, the presence of tumor-infiltrating lymphocytes predicted a better clinical response to neoadjuvant chemotherapy (131). Therefore, the existence of tumor-infiltrating lymphocytes can be regarded as a prognostic parameter for the prediction of the response to clinical treatment of patients with TNBC.

Immune checkpoint system. Tumor cells can evade the recognition and destruction by the host immune system through the immune checkpoint system; blocking the immune 
checkpoint system is a promising treatment for achieving effective antitumor immunity. PD-1 is a well-established immune checkpoint protein and cell-surface receptor that disrupts the T-cell response by triggering inhibitory pathways (132). Notably, PD-1 is expressed in $20 \%$ of TNBC tumors (133). PD-L1 is the ligand of PD-1, and is expressed in $58.6 \%$ of TNBC tumors $(66,134)$. PD-L2 is expressed on the surface of dendritic cells, macrophages, mast cells and B cells (135). Antibodies to inhibit PD-1 signaling are currently being assessed for clinical use. For example, pembrolizumab, a monoclonal antibody against PD-1, has demonstrated an overall response rate of $18.5 \%$ in a phase Ib study $(\mathrm{n}=32)$ of patients with PD-L1-positive TNBCs (66). Furthermore, a preliminary phase I trial study suggested that the monoclonal anti-PD-L1 antibody MPDL3280A prolonged progression-free survival time and produced durable therapeutic effects in certain patients with TNBC (136).

In addition, there is an association between the immune response and the Ras/MAPK pathway in TNBC. A study has indicated that the Ras/MAPK pathway negatively regulated antitumor immunity by affecting antigen presentation, including that of MHC-I, MHC-II and PD-1, and it was verified that a combination of MEK inhibition and PD-1/PD-L1 antibodies increased the effect of treatment in murine syngeneic tumor models (26). An additional study identified that an oncolytic viral therapy (NV1066) eliminated $>70 \%$ of the cells from all the TNBC cell lines tested by day 7, and effectively reduced the tumor size compared with control treatment groups (57 vs. $438 \mathrm{~mm} ; \mathrm{P}=0.002$ ) through downregulating the Ras/MAPK pathway (137).

\section{Conclusion}

TNBC is attracting increasing attention on account of its unique clinical pathology and molecular features. Chemotherapy remains the exclusive effective systemic treatment for patients with TNBC. These patients exhibit varied therapeutic responses and prognoses. Thus, individualized treatment and prognostic analysis in patients with TNBC can be difficult, particularly when this depends on conventional clinical and pathological features, including the histological grade, primary tumor size, lymph node metastasis status and ER/PR/HER2 expression. With the emergence of targeted therapy, screening more reliable molecular markers is imperative, and comprehensively understanding the signaling pathways that regulate biological behaviors may facilitate the establishment of a precise molecular classification for TNBC and effective therapeutic regimens.

In the present review, TNBC-associated tumorigenic signaling pathways were summarized in five categories, specifically RTKs and downstream signaling pathways, epithelial-to-mesenchymal transition and associated pathways, immunoregulatory tumor microenvironment, DNA damage repair pathways, and AR and coordinating pathways. These pathways are illustrated in Fig. 1 to demonstrate the interactions across the entire network, and the relevant drugs against specific pathways are summarized in Table I. Enhancing the understanding of the molecular heterogeneity of TNBCs can lay the foundation for the individualized treatment of patients with TNBC.
It is worth noting that a study concerning the efficacy of a number of biological agents, including bevacizumab, sunitinib, sorafenib, lapatinib, iniparib and cetuximab, in metastatic TNBCs indicated that a significant PFS improvement was obtained following treatment with bevacizumab or cetuximab, indicating the importance of targeted therapy. Regrettably, the impact of the other agents in the study on patient survival was not significant (138), possibly due to concurrent abnormalities occurring in a number of the patients. If that is correct, the concurrent inhibition of tumorigenic pathways may inhibit the cancer process (45). Therefore, the understanding of the signaling crosstalk and feedback among the TNBC-associated tumorigenic signaling pathways needs to be improved to allow effective treatments with tolerable side effects to be developed.

\section{Acknowledgements}

Not applicable.

\section{Funding}

This work was supported by the Key Projects in the National Science \& Technology Pillar Program (grant nos. 2015BA112B12 and 2015BA112B15), National Natural Science Foundation of China (grant nos.81472473 and 81272360) and Tianjin Municipal Commission of Science \& Technology Key Research Program (grant no. 13ZCZCSY20300).

\section{Availability of data and materials}

Not applicable.

\section{Authors' contributions}

NW led the review's designing, consulting and writing. JL and JY led the conception and review of the paper. JZhang, JZhao, KM, JuZ, and ZJ made contributions to the collection of relevant literature. All authors have read and approved the manuscript.

\section{Ethics approval and consent to participate}

Not applicable.

\section{Consent for publication}

Not applicable.

\section{Competing interests}

The authors declare that they have no competing interests.

\section{References}

1. Torre LA, Bray F, Siegel RL, Ferlay J, Lortet-Tieulent J and Jemal A: Global cancer statistics, 2012. CA Cancer J Clin 65: 87-108, 2015.

2. Brenton JD, Carey LA, Ahmed AA and Caldas C: Molecular classification and molecular forecasting of breast cancer: Ready for clinical application? J Clin Oncol 23: 7350-7360, 2005. 
3. Shah SP, Roth A, Goya R, Oloumi A, Ha G, Zhao Y, Turashvili G, Ding J, Tse K, Haffari G, et al: The clonal and mutational evolution spectrum of primary triple-negative breast cancers. Nature 486: 395-399, 2012

4. Lehmann BD, Bauer JA, Chen X, Sanders ME, Chakravarthy AB, Shyr Y and Pietenpol JA: Identification of human triple-negative breast cancer subtypes and preclinical models for selection of targeted therapies. J Clin Invest 121: 2750-2767, 2011.

5. Dent R, Trudeau M, Pritchard KI, Hanna WM, Kahn HK, Sawka CA, Lickley LA, Rawlinson E, Sun P and Narod SA: Triple-negative breast cancer: Clinical features and patterns of recurrence. Clin Cancer Res 13: 4429-4434, 2007.

6. Gluz O, Liedtke C, Gottschalk N, Pusztai L, Nitz U and Harbeck N: Triple-negative breast cancer-current status and future directions. Ann Oncol 20: 1913-1927, 2009.

7. Berry DA, Cirrincione C, Henderson IC, Citron ML, Budman DR, Goldstein LJ, Martino S, Perez EA, Muss HB, Norton L, et al: Estrogen-receptor status and outcomes of modern chemotherapy for patients with node-positive breast cancer. JAMA 295: $1658-1667,2006$

8. Nabholtz JM, Abrial C, Mouret-Reynier MA, Dauplat MM, Weber B, Gligorov J, Forest AM, Tredan O, Vanlemmens L, Petit T, et al: Multicentric neoadjuvant phase II study of panitumumab combined with an anthracycline/taxane-based chemotherapy in operable triple-negative breast cancer: Identification of biologically defined signatures predicting treatment impact. Ann Oncol 25: 1570-1577, 2014.

9. Torrisi R, Balduzzi A, Ghisini R, Rocca A, Bottiglieri L, Giovanardi F, Veronesi P, Luini A, Orlando L, Viale G, et al: Tailored preoperative treatment of locally advanced triple negative (hormone receptor negative and HER 2 negative) breast cancer with epirubicin, cisplatin, and infusional fluorouracil followed by weekly paclitaxel. Cancer Chemother Pharmacol 62 : 667-672, 2008

10. Burstein MD, Tsimelzon A, Poage GM, Covington KR Contreras A, Fuqua SA, Savage MI, Osborne CK, Hilsenbeck SG, Chang JC, et al: Comprehensive genomic analysis identifies novel subtypes and targets of triple-negative breast cancer. Clin Cancer Res 21: 1688-1698, 2015.

11. Tsimberidou AM, Iskander NG, Hong DS, Wheler JJ, Falchook GS, Fu S, Piha-Paul S, Naing A, Janku F, Luthra R, et al: Personalized medicine in a phase I clinical trials program: The MD Anderson cancer center initiative. Clin Cancer Res 18 : 6373-6383, 2012.

12. Jovanović B, Beeler JS, Pickup MW, Chytil A, Gorska AE, Ashby WJ, Lehmann BD, Zijlstra A, Pietenpol JA and Moses HL: Transforming growth factor beta receptor type III is a tumor promoter in mesenchymal-stem like triple negative breast cancer. Breast Cancer Res 16: R69, 2014.

13. Litzenburger BC, Creighton CJ, Tsimelzon A, Chan BT, Hilsenbeck SG, Wang T, Carboni JM, Gottardis MM, Huang F, Chang JC, et al: High IGF-IR activity in triple-negative breast cancer cell lines and tumorgrafts correlates with sensitivity to anti-IGF-IR therapy. Clin Cancer Res 17: 2314-2327, 2011.

14. Sharpe R, Pearson A, Herrera-Abreu MT, Johnson D, Mackay A, Welti JC, Natrajan R, Reynolds AR, Reis-Filho JS, Ashworth A and Turner NC: FGFR signaling promotes the growth of triple-negative and basal-like breast cancer cell lines both in vitro and in vivo. Clin Cancer Res 17 5275-5286, 2011

15. Spanheimer PM, Lorenzen AW, De Andrade JP, Kulak MV, Carr JC, Woodfield GW, Sugg SL and Weigel RJ: Receptor tyrosine kinase expression predicts response to sunitinib in breast cancer. Ann Surg Oncol 22: 4287-4294, 2015.

16. Yan S, Jiao X, Zou H and Li K: Prognostic significance of c-Met in breast cancer: A meta-analysis of 6010 cases. Diagn Pathol 10: 62, 2015.

17. Burness ML, Grushko TA and Olopade OI: Epidermal growth factor receptor in triple-negative and basal-like breast cancer: Promising clinical target or only a marker? Cancer J 16: 23-32, 2010.

18. Siziopikou KP, Ariga R, Proussaloglou KE, Gattuso P and Cobleigh M: The challenging estrogen receptor-negative/progesterone receptor-negative/HER-2-negative patient: A promising candidate for epidermal growth factor receptor-targeted therapy? Breast J 12: 360-362, 2006.

19. Bayraktar S and Glück S: Molecularly targeted therapies for metastatic triple-negative breast cancer. Breast Cancer Res Treat 138: 21-35, 2013.
20. Hsiao YC, Yeh MH, Chen YJ, Liu JF, Tang CH and Huang WC Lapatinib increases motility of triple-negative breast cancer cells by decreasing miRNA-7 and inducing Raf-1/MAPK-dependent interleukin-6. Oncotarget 6: 37965-37978, 2015.

21. Agazie YM and Hayman MJ: Molecular mechanism for a role of SHP2 in epidermal growth factor receptor signaling. Mol Cell Biol 23: 7875-7886, 2003

22. Matalkah F, Martin E, Zhao H and Agazie YM: SHP2 acts both upstream and downstream of multiple receptor tyrosine kinases to promote basal-like and triple-negative breast cancer. Breast Cancer Res 18: 2, 2016.

23. Kim HR, Jung KH, Im SA, Im YH, Kang SY, Park KH, Lee S, Kim SB, Lee KH, Ahn JS, et al: Multicentre phase II trial of bevacizumab combined with docetaxel-carboplatin for the neoadjuvant treatment of triple-negative breast cancer (KCSG BR-0905). Ann Oncol 24: 1485-1490, 2013.

24. Gerber B, Loibl S, Eidtmann H, Rezai M, Fasching PA, Tesch H, Eggemann H, Schrader I, Kittel K, Hanusch C, et al: Neoadjuvant bevacizumab and anthracycline-taxane-based chemotherapy in 678 triple-negative primary breast cancers; results from the geparquinto study (GBG 44). Ann Oncol 24: 2978-2984, 2013

25. Bartholomeusz C, Xie X, Pitner MK, Kondo K, Dadbin A, Lee J, Saso H, Smith PD, Dalby KN and Ueno NT: MEK inhibitor selumetinib (AZD6244; ARRY-142886) prevents lung metastasis in a triple-negative breast cancer xenograft model. Mol Cancer Ther 14: 2773-2781, 2015.

26. Giltnane JM and Balko JM: Rationale for targeting the Ras/MAPK pathway in triple-negative breast cancer. Discov Med 17: 275-283, 2014.

27. Bartholomeusz C, Gonzalez-Angulo AM, Liu P, Hayashi N, Lluch A, Ferrer-Lozano J and Hortobágyi GN: High ERK protein expression levels correlate with shorter survival in triple-negative breast cancer patients. Oncologist 17: 766-774, 2012.

28. Loi S, Dushyanthen S, Beavis PA, Salgado R, Denkert C, Savas P, Combs S, Rimm DL, Giltnane JM, Estrada MV, et al: RAS/MAPK activation is associated with reduced tumor-infiltrating lymphocytes in triple-negative breast cancer: Therapeutic cooperation between MEK and PD-1/PD-L1 immune checkpoint inhibitors. Clin Cancer Res 22: 1499-1509, 2016.

29. Rameh LE and Cantley LC: The role of phosphoinositide 3-kinase lipid products in cell function. J Biol Chem 274: 8347-8350, 1999

30. Baselga J: Targeting the phosphoinositide-3 (PI3) kinase pathway in breast cancer. Oncologist 16 (Suppl 1): S12-S19, 2011.

31. Cantley LC: The phosphoinositide 3-kinase pathway. Science 296: 1655-1657, 2002.

32. Salmena L, Carracedo A and Pandolfi PP: Tenets of PTEN tumor suppression. Cell 133: 403-414, 2008.

33. Meric-Bernstam F and Gonzalez-Angulo AM: Targeting the mTOR signaling network for cancer therapy. J Clin Oncol 27: 2278-2287, 2009 .

34. Cossu-Rocca P, Orrù S, Muroni MR, Sanges F, Sotgiu G, Ena S, Pira G, Murgia L, Manca A, Uras MG, et al: Analysis of PIK3CA mutations and activation pathways in triple negative breast cancer. PLoS One 10: e0141763, 2015.

35. Cancer Genome Atlas Network: Comprehensive molecular portraits of human breast tumours. Nature 490: 61-70, 2012.

36. Korkaya H, Paulson A, Charafe-Jauffret E, Ginestier C, Brown M, Dutcher J, Clouthier SG and Wicha MS: Regulation of mammary stem/progenitor cells by PTEN/Akt/beta-catenin signaling. PLoS Biol 7: e1000121, 2009.

37. Shrivastava S, Kulkarni P, Thummuri D, Jeengar MK, Naidu VG, Alvala M, Redddy GB and Ramakrishna S: Piperlongumine, an alkaloid causes inhibition of PI3K/Akt/mTOR signaling axis to induce caspase-dependent apoptosis in human triple-negative breast cancer cells. Apoptosis 19: 1148-1164, 2014

38. Chin YR, Yoshida T, Marusyk A, Beck AH, Polyak K and Toker A: Targeting Akt3 signaling in triple-negative breast cancer. Cancer Res 74: 964-973, 2014.

39. Montero JC, Esparis-Ogando A, Re-Louhau MF, Seoane S, Abad M, Calero R, Ocaña A and Pandiella A: Active kinase profiling, genetic and pharmacological data define mTOR as an important common target in triple-negative breast cancer. Oncogene 33: 148-156, 2014.

40. Baselga J, Campone M, Piccart M, Burris HA III, Rugo HS, Sahmoud T, Noguchi S, Gnant M, Pritchard KI, Lebrun F, et al: Everolimus in postmenopausal hormone-receptor-positive advanced breast cancer. N Engl J Med 366: 520-529, 2012. 
41. Beuvink I, Boulay A, Fumagalli S, Zilbermann F, Ruetz S, O'Reilly T, Natt F, Hall J, Lane HA and Thomas G: The mTOR inhibitor RAD001 sensitizes tumor cells to DNA-damaged induced apoptosis through inhibition of p21 translation. Cell 120: 747-759, 2005.

42. Singh J, Novik Y, Stein S, Volm M, Meyers M, Smith J, Omene C, Speyer J, Schneider R, Jhaveri K, et al: Phase 2 trial of everolimus and carboplatin combination in patients with triple negative metastatic breast cancer. Breast Cancer Res 16: R32, 2014.

43. Ganesan P, Moulder S, Lee JJ, Janku F, Valero V, Zinner RG, Naing A, Fu S, Tsimberidou AM, Hong D, et al: Triple-negative breast cancer patients treated at MD Anderson Cancer Center in phase I trials: Improved outcomes with combination chemotherapy and targeted agents. Mol Cancer Ther 13: 3175-3184, 2014.

44. Ibrahim YH, Garcia-Garcia C, Serra V, He L, Torres-Lockhart K Prat A, Anton P, Cozar P, Guzmán M, Grueso J, et al: PI3K inhibition impairs BRCA1/2 expression and sensitizes BRCA-proficient triple-negative breast cancer to PARP inhibition. Cancer Discov 2: 1036-1047, 2012.

45. Schuler M, Awada A, Harter P, Canon JL, Possinger K, Schmidt M, De Grève J, Neven P, Dirix L, Jonat W, et al: A phase II trial to assess efficacy and safety of afatinib in extensively pretreated patients with HER2-negative metastatic breast cancer. Breast Cancer Res Treat 134: 1149-1159, 2012

46. Bernsdorf M, Ingvar C, Jörgensen L, Tuxen MK, Jakobsen EH, Saetersdal A, Kimper-Karl ML, Kroman N, Balslev E and Ejlertsen B: Effect of adding gefitinib to neoadjuvant chemotherapy in estrogen receptor negative early breast cancer in a randomized phase II trial. Breast Cancer Res Treat 126: 463-470, 2011.

47. Mailliez A, Baldini C, Van JT, Servent V, Mallet Y and Bonneterre J: Nasal septum perforation: A side effect of bevacizumab chemotherapy in breast cancer patients. Br J Cancer 103: $772-775,2010$

48. Scott AJ, Messersmith WA and Jimeno A: Apatinib: A promising oral antiangiogenic agent in the treatment of multiple solid tumors. Drugs Today (Barc) 51: 223-229, 2015.

49. Hong DS, Garrido-Laguna I, Ekmekcioglu S, Falchook GS Naing A, Wheler JJ, Fu S, Moulder SL, Piha-Paul S, Tsimberidou AM, et al: Dual inhibition of the vascular endothelial growth factor pathway: A phase 1 trial evaluating bevacizumab and AZD2171 (cediranib) in patients with advanced solid tumors Cancer 120: 2164-2173, 2014.

50. Tolaney SM, Tan S, Guo H, Barry W, Van Allen E, Wagle N, Brock J, Larrabee K, Paweletz C, Ivanova E, et al: Phase II study of tivantinib (ARQ 197) in patients with metastatic triple-negative breast cancer. Invest New Drugs 33: 1108-1114, 2015.

51. Tolaney SM, Ziehr DR, Guo H, Ng MR, Barry WT, Higgins MJ, Isakoff SJ, Brock JE, Ivanova EV, Paweletz CP, et al: Phase II and biomarker study of cabozantinib in metastatic triple-negative breast cancer patients. Oncologist 22: 25-32, 2017.

52. Soria JC, DeBraud F, Bahleda R, Adamo B, Andre F, Dienstmann R, Delmonte A, Cereda R, Isaacson J, Litten J, et al: Phase I/IIa study evaluating the safety, efficacy, pharmacokinetics, and pharmacodynamics of lucitanib in advanced solid tumors. Ann Oncol 25: 2244-2251, 2014.

53. Wu YL, Zhang LI, Trandafir L, Dong T, Duval V, Hazell K and $\mathrm{Xu}$ B: Phase I study of the Pan-PI3K inhibitor buparlisib in adult chinese patients with advanced solid tumors. Anticancer Res 36: 6185-6194, 2016

54. Juric D, Krop I, Ramanathan RK, Wilson TR, Ware JA, Sanabria Bohorquez SM, Savage HM, Sampath D, Salphati L, Lin RS, et al: Phase I dose-escalation study of taselisib, an oral PI3K inhibitor, in patients with advanced solid tumors. Cancer Discov 7: 704-715, 2017.

55. Tamura K, Hashimoto J, Tanabe Y, Kodaira M, Yonemori K, Seto T, Hirai F, Arita S, Toyokawa G, Chen L, et al: Safety and tolerability of AZD5363 in Japanese patients with advanced solic tumors. Cancer Chemother Pharmacol 77: 787-795, 2016.

56. Doi T, Tamura K, Tanabe Y, Yonemori K, Yoshino T, Fuse N, Kodaira M, Bando H, Noguchi K, Shimamoto T and Ohtsu A: Phase 1 pharmacokinetic study of the oral pan-AKT inhibitor MK-2206 in Japanese patients with advanced solid tumors. Cancer Chemother Pharmacol 76: 409-416, 2015.

57. Saura C, Roda D, Roselló S, Oliveira M, Macarulla T, Pérez-Fidalgo JA, Morales-Barrera R, Sanchis-García JM, Musib L, Budha N, et al: A first-in-human phase I study of the ATP-competitive AKT inhibitor ipatasertib demonstrates robust and safe targeting of AKT in patients with solid tumors. Cancer Discov 7: 102-113, 2017.
58. Pascual T, Apellániz-Ruiz M, Pernaut C, Cueto-Felgueroso C, Villalba P, Álvarez C, Manso L, Inglada-Pérez L, Robledo M, Rodríguez-Antona C and Ciruelos E: Polymorphisms associated with everolimus pharmacokinetics, toxicity and survival in metastatic breast cancer. PLoS One 12: e0180192, 2017.

59. Chiu JW, Hotte SJ, Kollmannsberger CK, Renouf DJ, Cescon DW, Hedley D, Chow S, Moscow J, Chen Z, Perry M, et al: A phase I trial of ANG1/2-Tie2 inhibitor trebaninib (AMG386) and temsirolimus in advanced solid tumors (PJC008/NCI 9041). Invest New Drugs 34: 104-111, 2016.

60. Schwartzberg LS, Yardley DA, Elias AD, Patel M, LoRusso P, Burris HA, Gucalp A, Peterson AC, Blaney ME, Steinberg JL, et al: A Phase I/Ib study of enzalutamide alone and in combination with endocrine therapies in women with advanced breast cancer. Clin Cancer Res 23: 4046-4054, 2017.

61. Drew Y, Ledermann J, Hall G, Rea D, Glasspool R, Highley M, Jayson G, Sludden J, Murray J, Jamieson D, et al: Phase 2 multicentre trial investigating intermittent and continuous dosing schedules of the poly(ADP-ribose) polymerase inhibitor rucaparib in germline BRCA mutation carriers with advanced ovarian and breast cancer. Br J Cancer 114: e21, 2016.

62. O'Shaughnessy J, Schwartzberg L, Danso MA, Miller KD, Rugo HS, Neubauer M, Robert N, Hellerstedt B, Saleh M, Richards P, et al: Phase III study of iniparib plus gemcitabine and carboplatin versus gemcitabine and carboplatin in patients with metastatic triple-negative breast cancer. J Clin Oncol 32: 3840-3847, 2014

63. Nishikawa T, Matsumoto K, Tamura K, Yoshida H, Imai Y, Miyasaka A, Onoe T, Yamaguchi S, Shimizu C, Yonemori K, et al: Phase 1 dose-escalation study of single-agent veliparib in Japanese patients with advanced solid tumors. Cancer Sci 108: 1834-1842, 2017

64. de Bono J, Ramanathan RK, Mina L, Chugh R, Glaspy J, Rafii S, Kaye S, Sachdev J, Heymach J, Smith DC, et al: Phase I, dose-escalation, two-part trial of the PARP inhibitor talazoparib in patients with advanced germline BRCA1/2 mutations and selected sporadic cancers. Cancer Discov 7: 620-629, 2017.

65. Robson M, Im SA, Senkus E, Xu B, Domchek SM, Masuda N, Delaloge S, Li W, Tung N, Armstrong A, et al: Olaparib for metastatic breast cancer in patients with a germline BRCA mutation. N Engl J Med 377: 523-533, 2017.

66. Nanda R, Chow LQ, Dees EC, Berger R, Gupta S, Geva R, Pusztai L, Pathiraja K, Aktan G, Cheng JD, et al: Pembrolizumab in patients with advanced triple-negative breast cancer: Phase Ib KEYNOTE-012 study. J Clin Oncol 34: 2460-2467, 2016.

67. Lee JM, Cimino-Mathews A, Peer CJ, Zimmer A, Lipkowitz S, Annunziata CM, Cao L, Harrell MI, Swisher EM, Houston N, et al: Safety and clinical activity of the programmed death-ligand 1 inhibitor durvalumab in combination with poly (ADP-Ribose) polymerase inhibitor olaparib or vascular endothelial growth factor receptor 1-3 inhibitor cediranib in women's cancers: A dose-escalation, phase I study. J Clin Oncol 35: 2193-2202, 2017.

68. Hoeflich KP, O'Brien C, Boyd Z, Cavet G, Guerrero S, Jung K, Januario T, Savage H, Punnoose E, Truong T, et al: In vivo antitumor activity of MEK and phosphatidylinositol 3-kinase inhibitors in basal-like breast cancer models. Clin Cancer Res 15: 4649-4664, 2009.

69. Britten CD: PI3K and MEK inhibitor combinations: Examining the evidence in selected tumor types. Cancer Chemother Pharmacol 71: 1395-1409, 2013.

70. Nieto MA: Epithelial plasticity: A common theme in embryonic and cancer cells. Science 342: 1234850, 2013.

71. Al Moustafa AE, Achkhar A and Yasmeen A: EGF-receptor signaling and epithelial-mesenchymal transition in human carcinomas. Front Biosci (Schol Ed) 4: 671-684, 2012

72. Gonzalez DM and Medici D: Signaling mechanisms of the epithelial-mesenchymal transition. Sci Signal 7: re8, 2014.

73. Guarino M: Src signaling in cancer invasion. J Cell Physiol 223 14-26, 2010.

74. Hung CM, Kuo DH, Chou CH, Su YC, Ho CT and Way TD: Osthole suppresses hepatocyte growth factor (HGF)-induced epithelial-mesenchymal transition via repression of the c-Met/Akt/mTOR pathway in human breast cancer cells. J Agric Food Chem 59: 9683-9690, 2011

75. Kang Y and Massagué J: Epithelial-mesenchymal transitions: Twist in development and metastasis. Cell 118: 277-279, 2004.

76. Sivakumar R, Koga H, Selvendiran K, Maeyama M, Ueno T and Sata M: Autocrine loop for IGF-I receptor signaling in SLUG-mediated epithelial-mesenchymal transition. Int J Oncol 34: 329-338, 2009. 
77. Vincent-Salomon A and Thiery JP: Host microenvironment in breast cancer development: Epithelial-mesenchymal transition in breast cancer development. Breast Cancer Res 5: 101-106, 2003.

78. De Craene B and Berx G: Regulatory networks defining EMT during cancer initiation and progression. Nat Rev Cancer 13: 97-110, 2013.

79. Thiery JP: Epithelial-mesenchymal transitions in tumour progression. Nat Rev Cancer 2: 442-454, 2002.

80. Foroni C, Broggini M, Generali D and Damia G: Epithelial-mesenchymal transition and breast cancer: Role, molecular mechanisms and clinical impact. Cancer Treat Rev 38: 689-697, 2012

81. Prat A, Parker JS, Karginova O, Fan C, Livasy C, Herschkowitz JI, $\mathrm{He} \mathrm{X}$ and Perou CM: Phenotypic and molecular characterization of the claudin-low intrinsic subtype of breast cancer. Breast Cancer Res 12: R68, 2010.

82. Mani SA, Guo W, Liao MJ, Eaton EN, Ayyanan A, Zhou AY, Brooks M, Reinhard F, Zhang CC, Shipitsin M, et al: The epithelial-mesenchymal transition generates cells with properties of stem cells. Cell 133: 704-715, 2008

83. Singh R and Mo YY: Role of microRNAs in breast cancer. Cancer Biol Ther 14: 201-212, 2013.

84. Rhodes LV, Martin EC, Segar HC, Miller DF, Buechlein A, Rusch DB, Nephew KP, Burow ME and Collins-Burow BM: Dual regulation by microRNA-200b-3p and microRNA-200b-5p in the inhibition of epithelial-to-mesenchymal transition in triple-negative breast cancer. Oncotarget 6: 16638-16652, 2015.

85. Ito K, Park SH, Nayak A, Byerly JH and Irie HY: PTK6 inhibition suppresses metastases of triple-negative breast cancer via SNAIL-Dependent E-cadherin regulation. Cancer Res 76 4406-4417, 2016.

86. Al-Hajj M, Wicha MS, Benito-Hernandez A, Morrison SJ and Clarke MF: Prospective identification of tumorigenic breast cancer cells. Proc Natl Acad Sci USA 100: 3983-3988, 2003.

87. Ginestier C, Hur MH, Charafe-Jauffret E, Monville F, Dutcher J, Brown M, Jacquemier J, Viens P, Kleer CG, Liu S, et al: ALDH1 is a marker of normal and malignant human mammary stem cells and a predictor of poor clinical outcome. Cell Stem Cell 1: 555-567, 2007

88. Rhodes LV, Tate CR, Segar HC, Burks HE, Phamduy TB, Hoang V, Elliott S, Gilliam D, Pounder FN, Anbalagan M, et al: Suppression of triple-negative breast cancer metastasis by pan-DAC inhibitor panobinostat via inhibition of ZEB family of EMT master regulators. Breast Cancer Res Treat 145: 593-604, 2014.

89. Kahn M: Can we safely target the WNT pathway? Nat Rev Drug Discov 13: 513-532, 2014

90. Conacci-Sorrell M, Simcha I, Ben-Yedidia T, Blechman J, Savagner P and Ben-Ze'ev A: Autoregulation of E-cadherin expression by cadherin-cadherin interactions: The roles of beta-catenin signaling, Slug, and MAPK. J Cell Biol 163: 847-857, 2003.

91. Howe LR, Watanabe O, Leonard J and Brown AM: Twist is up-regulated in response to Wntl and inhibits mouse mammary cell differentiation. Cancer Res 63: 1906-1913, 2003.

92. MacDonald BT, Tamai K and He X: Wnt/beta-catenin signaling: Components, mechanisms, and diseases. Dev Cell 17: 9-26, 2009.

93. Dey N, Barwick BG, Moreno CS, Ordanic-Kodani M, Chen Z, Oprea-Ilies G, Tang W, Catzavelos C, Kerstann KF, Sledge GW Jr, et al: Wnt signaling in triple negative breast cancer is associated with metastasis. BMC Cancer 13: 537, 2013.

94. Li Y, Li PK, Roberts MJ, Arend RC, Samant RS and Buchsbaum DJ: Multi-targeted therapy of cancer by niclosamide: A new application for an old drug. Cancer Lett 349: 8-14, 2014.

95. Londoño-Joshi AI, Arend RC, Aristizabal L, Lu W, Samant RS, Metge BJ, Hidalgo B, Grizzle WE, Conner M, Forero-Torres A, et al: Effect of niclosamide on basal-like breast cancers. Mol Cancer Ther 13: 800-811, 2014

96. Koval A, Ahmed K and Katanaev VL: Inhibition of Wnt signalling and breast tumour growth by the multi-purpose drug suramin through suppression of heterotrimeric $\mathrm{G}$ proteins and Wnt endocytosis. Biochem J 473: 371-381, 2016.

97. Nam JS, Suchar AM, Kang MJ, Stuelten CH, Tang B, Michalowska AM, Fisher LW, Fedarko NS, Jain A, Pinkas J, et al: Bone sialoprotein mediates the tumor cell-targeted prometastatic activity of transforming growth factor beta in a mouse model of breast cancer. Cancer Res 66: 6327-6335, 2006.

98. Zu X, Zhang Q, Cao R, Liu J, Zhong J, Wen G and Cao D: Transforming growth factor- $\beta$ signaling in tumor initiation, progression and therapy in breast cancer: An update. Cell Tissue Res 347: 73-84, 2012.
99. Shi Y and Massagué J: Mechanisms of TGF-beta signaling from cell membrane to the nucleus. Cell 113: 685-700, 2003.

100. Katz LH, Li Y, Chen JS, Muñoz NM, Majumdar A, Chen J and Mishra L: Targeting TGF- $\beta$ signaling in cancer. Expert Opin Ther Targets 17: 743-760, 2013.

101. Valcourt U, Kowanetz M, Niimi H,Heldin CH and Moustakas A TGF-beta and the Smad signaling pathway support transcriptomic reprogramming during epithelial-mesenchymal cell transition. Mol Biol Cell 16: 1987-2002, 2005.

102. Massagué J: TGFbeta in cancer. Cell 134: 215-230, 2008.

103. Kim S, Lee J, Jeon M, Lee JE and Nam SJ: Zerumbone suppresses the motility and tumorigenecity of triple negative breast cancer cells via the inhibition of TGF- $\beta 1$ signaling pathway. Oncotarget 7: 1544-1558, 2016.

104. Wahdan-Alaswad R, Harrell JC, Fan Z, Edgerton SM, Liu B and Thor AD: Metformin attenuates transforming growth factor beta (TGF- $\beta$ ) mediated oncogenesis in mesenchymal stem-like/claudin-low triple negative breast cancer. Cell Cycle 15: 1046-1059, 2016

105. Bhola NE, Balko JM, Dugger TC, Kuba MG, Sánchez V, Sanders M, Stanford J, Cook RS and Arteaga CL: TGF- $\beta$ inhibition enhances chemotherapy action against triple-negative breast cancer. J Clin Invest 123: 1348-1358, 2013

106. Purrington KS, Visscher DW, Wang C, Yannoukakos D, Hamann U, Nevanlinna H, Cox A, Giles GG, Eckel-Passow JE, Lakis S, et al: Genes associated with histopathologic features of triple negative breast tumors predict molecular subtypes. Breast Cancer Res Treat 157: 117-131, 2016.

107. Collins LC, Cole KS, Marotti JD, Hu R, Schnitt SJ and Tamimi RM: Androgen receptor expression in breast cancer in relation to molecular phenotype: Results from the nurses' health study. Mod Pathol 24: 924-931, 2011.

108. Liao DJ and Dickson RB: Roles of androgens in the development, growth, and carcinogenesis of the mammary gland. J Steroid Biochem Mol Biol 80: 175-189, 2002.

109. Hickey TE, Robinson JL, Carroll JS and Tilley WD: Minireview: the androgen receptor in breast tissues: Growth inhibitor, tumor suppressor, oncogene? Mol Endocrinol 26: 1252-1267, 2012.

110. Gucalp A and Traina TA: Triple-negative breast cancer: Role of the androgen receptor. Cancer J 16: 62-65, 2010.

111. Gucalp A, Tolaney S, Isakoff SJ, Ingle JN, Liu MC, Carey LA, Blackwell K, Rugo H, Nabell L, Forero A, et al: Phase II trial of bicalutamide in patients with androgen receptor-positive, estrogen receptor-negative metastatic breast cancer. Clin Cancer Res 19: 5505-5512, 2013

112. Lehmann BD, Bauer JA, Schafer JM, Pendleton CS, Tang L, Johnson KC, Chen X, Balko JM, Gómez H, Arteaga CL, et al: PIK3CA mutations in androgen receptor-positive triple negative breast cancer confer sensitivity to the combination of PI3K and androgen receptor inhibitors. Breast Cancer Res 16: 406 , 2014.

113. Cuenca-López Md, Montero JC, Morales JC, Prat A, Pandiella A and Ocana A: Phospho-kinase profile of triple negative breast cancer and androgen receptor signaling. BMC Cancer 14: 302, 2014.

114. Maugeri-Saccà M, Bartucci $M$ and De Maria R: DNA damage repair pathways in cancer stem cells. Mol Cancer Ther 11: 1627-1636, 2012.

115. Pierce AJ, Stark JM, Araujo FD, Moynahan ME, Berwick M and Jasin M: Double-strand breaks and tumorigenesis. Trends Cell Biol 11: S52-S59, 2001

116. Powell SN and Kachnic LA: Roles of BRCA1 and BRCA2 in homologous recombination, DNA replication fidelity and the cellular response to ionizing radiation. Oncogene 22: 5784-5791, 2003.

117. Bouwman P and Jonkers J: The effects of deregulated DNA damage signalling on cancer chemotherapy response and resistance. Nat Rev Cancer 12: 587-598, 2012.

118. Stevens KN, Vachon CM and Couch FJ: Genetic susceptibility to triple-negative breast cancer. Cancer Res 73: 2025-2030, 2013.

119. Atchley DP, Albarracin CT, Lopez A, Valero V, Amos CI, Gonzalez-Angulo AM, Hortobagyi GN and Arun BK: Clinical and pathologic characteristics of patients with BRCA-positive and BRCA-negative breast cance. J Clin Oncol 26: 4282-4288, 2008

120. Goodwin PJ,Phillips KA, West DW,Ennis M,HopperJL,JohnEM, O'Malley FP, Milne RL, Andrulis IL, Friedlander ML, et al: Breast cancer prognosis in BRCA1 and BRCA 2 mutation carriers: An international prospective breast cancer family registry population-based cohort study. J Clin Oncol 30: 19-26, 2012. 
121. Stoppa-Lyonnet D, Ansquer Y, Dreyfus H, Gautier C, Gauthier-Villars M, Bourstyn E, Clough KB, Magdelénat H, Pouillart P, Vincent-Salomon A, et al: Familial invasive breast cancers: Worse outcome related to BRCA1 mutations. J Clin Oncol 18: 4053-4059, 2000.

122. Rummel S, Varner E, Shriver CD and Ellsworth RE: Evaluation of BRCA1 mutations in an unselected patient population with triple-negative breast cancer. Breast Cancer Res Treat 137: $119-125,2013$

123. Hoeijmakers JH: Genome maintenance mechanisms for preventing cancer. Nature 411: 366-374, 2001.

124. O'Shaughnessy J, Osborne C, Pippen JE, Yoffe M, Patt D, Rocha C, Koo IC, Sherman BM and Bradley C: Iniparib plus chemotherapy in metastatic triple-negative breast cancer. $\mathrm{N}$ Engl J Med 364: 205-214, 2011.

125. Dent RA, Lindeman GJ, Clemons M, Wildiers H, Chan A McCarthy NJ, Singer CF, Lowe ES, Watkins CL and Carmichael J: Phase I trial of the oral PARP inhibitor olaparib in combination with paclitaxel for first- or second-line treatment of patients with metastatic triple-negative breast cancer. Breast Cancer Res 15: R88, 2013.

126. Ollier M, Radosevic-Robin N, Kwiatkowski F, Ponelle F, Viala S, Privat M, Uhrhammer N, Bernard-Gallon D, Penault-Llorca F, Bignon YJ and Bidet Y: DNA repair genes implicated in triple negative familial non-BRCA1/2 breast cancer predisposition. Am J Cancer Res 5: 2113-2126, 2015.

127. Alshareeda AT, Negm OH, Aleskandarany MA, Green AR, Nolan C, TigHhe PJ, Madhusudan S, Ellis IO and Rakha EA: Clinical and biological significance of RAD51 expression in breast cancer: A key DNA damage response protein. Breast Cancer Res Treat 159: 41-53, 2016.

128. Loi S, Michiels S, Salgado R, Sirtaine N, Jose V, Fumagalli D, Kellokumpu-Lehtinen PL, Bono P, Kataja V, Desmedt C, et al: Tumor infiltrating lymphocytes are prognostic in triple negative breast cancer and predictive for trastuzumab benefit in early breast cancer: Results from the FinHER trial. Ann Oncol 25: 1544-1550, 2014.

129. Adams S, Gray RJ, Demaria S, Goldstein L, Perez EA, Shulman LN, Martino S, Wang M, Jones VE and Saphner TJ: Prognostic value of tumor-infiltrating lymphocytes in triple-negative breast cancers from two phase III randomized adjuvant breast cancer trials: ECOG 2197 and ECOG 1199. J Clin Oncol 32: 2959-2966, 2014.
130. Loi S, Sirtaine N, Piette F, Salgado R, Viale G, Van Eenoo F, Rouas G, Francis P, Crown JP and Hitre E, et al: Prognostic and predictive value of tumor-infiltrating lymphocytes in a phase III randomized adjuvant breast cancer trial in node-positive breast cancer comparing the addition of docetaxel to doxorubicin with doxorubicin-based chemotherapy: BIG 02-98. J Clin Oncol 31: 860-867, 2013

131. Adams S, Goldstein LJ, Sparano JA, Demaria S and Badve SS: Tumor infiltrating lymphocytes (TILs) improve prognosis in patients with triple negative breast cancer (TNBC) Oncoimmunology 4: e985930, 2015.

132. Criscitiello $\mathrm{C}$ and Curigliano G: Immunotherapy of breast cancer. Prog Tumor Res 42: 30-43, 2015.

133. Mittendorf EA, Philips AV, Meric-Bernstam F, Qiao N, Wu Y, Harrington S, Su X, Wang Y, Gonzalez-Angulo AM, Akcakanat A, et al: PD-L1 expression in triple-negative breast cancer. Cancer Immunol Res 2: 361-370, 2014.

134. Dong H, Strome SE, Salomao DR, Tamura H, Hirano F, Flies DB, Roche PC, Lu J, Zhu G, Tamada K, et al: Tumor-associated B7-H1 promotes T-cell apoptosis: A potential mechanism of immune evasion. Nat Med 8: 793-800, 2002.

135. Topalian SL, Hodi FS, Brahmer JR, Gettinger SN, Smith DC, McDermott DF, Powderly JD, Carvajal RD, Sosman JA, Atkins MB, et al: Safety, activity, and immune correlates of anti-PD-1 antibody in cancer. N Engl J Med 366: 2443-2454, 2012.

136. Immunotherapy slows TNBC progression. Cancer Discov 5: 570,2015

137. Gholami S, Chen CH, Gao S, Lou E, Fujisawa S, Carson J, Nnoli JE, Chou TC, Bromberg J and Fong Y: Role of MAPK in oncolytic herpes viral therapy in triple-negative breast cancer. Cancer Gene Ther 21: 283-289, 2014.

138. Bramati A, Girelli S, Torri V, Farina G, Galfrascoli E, Piva S, Moretti A, Dazzani MC, Sburlati P and La Verde NM: Efficacy of biological agents in metastatic triple-negative breast cancer. Cancer Treat Rev 40: 605-613, 2014.

This work is licensed under a Creative Commons Attribution-NonCommercial-NoDerivatives 4.0 International (CC BY-NC-ND 4.0) License. 